\title{
Assessment of Patient Satisfaction with Pharmaceutical Care Services in Community Pharmacies within Abuja
}

\author{
Onavbavba Godspower ${ }^{1 *}$, Danraka Abubakar $\mathrm{M}^{1}$, Galadima Isa $\mathrm{H}^{1}$, Isibor Aisosa $\mathrm{A}^{2}$
}

${ }^{1}$ National Institute for Pharmaceutical Research and Development, Idu, P.M.B 21 Garki, Abuja, Nigeria

${ }^{2}$ Pharmacists Council of Nigeria, Idu, P.M.B. 415 Garki, Abuja, Nigeria

DOI: $\underline{10.36347 / \text { sajp.2020.v09i02.001 }}$

| Received: 20.01.2020 | Accepted: 27.01.2020 | Published: 08.02.2020

*Corresponding author: Onavbavba Godspower

Abstract

Satisfaction consist of a cognitive evaluation of an emotional response to the structure, process and outcome of a system. Patient satisfaction is now being used as an indicator of quality of health care services. The patronage of patients to a particular pharmacy will depend on the level of satisfaction they received from that pharmacy. The objectives of this study were to assess patient satisfaction with pharmaceutical care services in community pharmacies within Abuja metropolis and also to compare satisfaction obtained across different community pharmacies. A cross-sectional survey was conducted with a sample size of 500 participants at 10 randomly selected community pharmacies in Abuja, Nigeria. A self-completion questionnaire that employed a Likert-type scale was used. Data were used to calculate scores on a scale that ranged from 1 to 5, with an assumed midpoint of 3.0. Descriptive statistics on the sample characteristics and questionnaire items were computed which include means, standard deviations, frequency distributions, and cross tabulation. A total of 500 questionnaires were administered, Response rate was $70.8 \%$. The mean response for all the responses was $3.72 \pm 0.88$. The item that received the highest satisfaction rating was "how well the pharmacists instruct you about how to take your medications" with a mean score of 4.11 . The factor loading for the instrument ranges from 0.539 to 0.753 while the Cronbach's alpha for the instrument was 0.899 . The study revealed that patients were satisfied with the level of care given to them by the community pharmacists within the city of Abuja, and satisfaction varies from one pharmacy to the other.

Keywords: Satisfaction, Patient, Community Pharmacy, Pharmacists, Abuja.

Copyright @ 2020: This is an open-access article distributed under the terms of the Creative Commons Attribution license which permits unrestricted use, distribution, and reproduction in any medium for non-commercial use (NonCommercial, or CC-BY-NC) provided the original author and source are credited.

\section{INTRODUCTION}

Pharmacy practice has evolved as a caring profession and the focus of that caring has shifted from the drug product to the patient [1]. In this regard, pharmacy practice is now patient oriented. Pharmacy practice has successful evolved from various stages, it started with the apothecary model which was the first stage. The second stage of pharmacy practice was the compounding model after which the practice of pharmacy then evolved into the distribution model followed by the clinical pharmacy model. Currently the practice of pharmacy has now shifted from the clinical pharmacy model to the pharmaceutical care model. The pharmaceutical care model is regarded as the fifth stage in the transition of pharmacy practice and it is characterized with taking responsibility in the performance of clinical functions [2]. Pharmaceutical care is a collaborative process with the prospect to prevent or identify drug and health related problems. The role of pharmaceutical care requires that pharmacists apply higher level of drug knowledge to solve drug therapy problems. Drug therapy problem is regarded as the heart and soul of pharmaceutical care. Helpler and Strand [3] adopted four basic components as the philosophy of pharmaceutical care and they include social need, patient-centered care, caring and pharmacists' responsibilities.

The American Pharmaceutical Association described pharmaceutical care as patient-centered, outcomes oriented pharmacy practice that requires pharmacists to work in collaboration with the patient and the patient's other healthcare providers so as to promote health, prevent disease, and to assess, monitor, initiate, and modify medication use to assure that drug therapy regimens are safe and effective [4]. The practice of pharmaceutical care originated from the United State of America and the goal is to optimize the patient's health-related quality of life, and achieve positive clinical outcomes within realistic, economic expenditures. Three basic components of 
pharmaceutical care are: assessment of patient needs; development of a care plan; and follow up evaluation. Oparah [2] has described six steps as the process of carrying out pharmaceutical care of which the steps are similar with that of Cipolle et al., [5]. The first step involved in pharmaceutical care is the establishment of a therapeutic relation. Therapeutic relationship can be established by greeting the patient, show empathy and then proceed to ask the patient how he or she feels. By so doing a therapeutic relationship has been initiated. The pharmacist then proceeds to introduce the concept of pharmaceutical care to the patient. The second step involve the collection of patients specific subjective and objective data, the data collected are then evaluated so as to identify health and drug therapy problems. The next stage is the development and implementation of pharmaceutical care plans followed by the evaluation of the interventions and follow-up. The last stage is the documentation of activities. When there is no documentation, it is assumed that no work has been done. Documentation provides evidence for what was done, audit trail, and continuity of care when another pharmacist is on duty. Three types of records can be generated from pharmaceutical care documentation [5]. These records include pharmaceutical care patient chart, created primarily for the pharmacist use; patient's personalized pharmaceutical care plan, generated for patient's use; and practice management report that is used to manage the practice. Pascoe [6] defined patient satisfaction as a function of patient expectations and perceptions of the services rendered. It was assumed that satisfaction consist of a cognitive evaluation of an emotional response to the structure, process and outcome of a system. Patient satisfaction is now being used as an indicator of quality of health care services [7-9]. The patronage of patient to a particular pharmacy will depend on the level of satisfaction they received from that pharmacy. Patient satisfaction affect adherence and also the image of the pharmacist and pharmacy profession is affected by the level of satisfaction a patient receives [2]. In a survey done in a Nigerian teaching hospital to assess patient satisfaction with pharmaceutical services, it was reported that the respondents received low satisfaction with the overall services of the pharmacy department [10]. Other Nigerian studies done in the hospital setting has reported that patients were satisfied with pharmaceutical care services [11-13]. In the community setting, while two studies in Nigeria reported that patients were satisfied with pharmaceutical services $[14,15]$, another study reported that patients were most satisfied with the pharmacists' professional attitude but dissatisfied with the provision of nondrug services in the community pharmacy [16]. There is therefore the need to conduct further study to gather more data on patient satisfaction with pharmaceutical care services in community pharmacies in Nigeria. A literature search further revealed that no study has been done relating to patient satisfaction with pharmaceutical care services in Abuja. While previous studies on patient satisfaction with pharmaceutical care services in community pharmacy in Nigeria was conducted in just one pharmacy, there is therefore the need to carry out satisfaction assessment across different community pharmacies. The objectives of this study were therefore to assess patient satisfaction with pharmaceutical care services in community pharmacies within Abuja metropolis and also to compare satisfaction obtained across different community pharmacies.

\section{METHODS Study Setting}

A cross sectional randomized sampling was conducted in 10 different community pharmacies located within Abuja metropolis. The community pharmacies were randomly chosen. Abuja is the capital city of Nigeria located within the Federal Capital Territory. Abuja became the capital of Nigeria on $12^{\text {th }}$ of December 1991 and its population was 776,298 as at 2006 census. However, as at 2016, the population of Abuja was estimated to be six million. Abuja is one of the fastest growing cities in the world with an annual growth of $35 \%$.

\section{Patients/Participants}

Patients who visited the various pharmacies for prescription filling were investigated in the period of the study. The inclusion criteria were: patients of the age of 21 and above, patients must have been using the particular pharmacy for at least a period of one month, and consent to participate was sort from the patients before administering the questionnaire to them.

\section{Sample Size}

A convenient sampling was done, of which a total of 500 questionnaires were distributed to the 10 community pharmacies used for the study. 50 questionnaires were used for each of the community pharmacies.

\section{Data Collection Procedures}

The data collected were socio demographic characteristics such as age, sex, marital status, level of education, and job occupation along with patient satisfaction. Patient satisfaction with pharmaceutical care services was assessed as humanistic outcome, this assessment was based on twenty item questionnaire developed by Larson et al [17] with slight modification and reduction in the number of items to 11. Likert type scale of 1 to 5 was used as follow; excellent $=5$, very $\operatorname{good}=4$, good $=3$, fair $=2$, and poor $=1$. The purpose of the questionnaire was properly explained to the patients before the administration of the questionnaire to them. Some of the respondents completed the questionnaire at the pharmacy while others took the questionnaire home to fill and return.

\section{Data Analysis}

Data were appropriately entered into Statistical Package for Social Science (SPSS) version 21, 
descriptive statistics such as mean, standard deviation, frequency, percentage, as well as inferential statistics and reliability were conducted.

\section{RESULTS}

\section{Socio Demographic characteristics}

Out of 500 questionnaires distributed, 380

were completed and returned. After sorting out, 26 of the completed questionnaires were excluded because they were not properly filled. Only 354 questionnaires were usable and included in the analysis, giving a response rate of $70.8 \% .23 .7 \%$ of the respondents were within the age of 26 to 30 years, $53.1 \%$ were male, $52.0 \%$ were married, $81.1 \%$ had post-secondary education, and $32.8 \%$ were civil servant. See details in Table-1 below.

Table-1: Socio demographic characteristics

\begin{tabular}{|l|l|}
\hline Variables n $=354$ & Frequency (\%) \\
\hline Age & \\
\hline $21-25$ & $80(22.6)$ \\
\hline $26-30$ & $84(23.7)$ \\
\hline $31-35$ & $83(16.1)$ \\
\hline $36-40$ & $45(12.7)$ \\
\hline $41-45$ & $43(12.1)$ \\
\hline $46-50$ & $18(5.1)$ \\
\hline 51 and above & $27(7.6)$ \\
\hline Sex & \\
\hline Male & $188(53.1)$ \\
\hline Female & $166(46.9)$ \\
\hline Marital Status & \\
\hline Single & $152(42.9)$ \\
\hline Married & $184(52.0)$ \\
\hline Divorced/separated & $8(2.3)$ \\
\hline Widowed & $9(2.5)$ \\
\hline Cohabiting & $1(0.3)$ \\
\hline Educational level & \\
\hline No formal education & $2(0.6)$ \\
\hline Primary education & $7(2.0)$ \\
\hline Secondary education & $58(16.4)$ \\
\hline Post-secondary education & $287(81.1)$ \\
\hline Job occupation & \\
\hline Unemployed & $20(5.6)$ \\
\hline Civil servant & $116(32.8)$ \\
\hline Student & $55(15.5)$ \\
\hline Retired & $14(4.0)$ \\
\hline Trader/self-employed & $100(28.2)$ \\
\hline Others & $49(13.8)$ \\
\hline & \\
\hline & \\
\hline
\end{tabular}

\section{Satisfaction Assessment}

Scores for satisfaction was computed on scale with a range of 1 to 5, with an assumed midpoint of 3 . Satisfaction was above average in all the items assessed. The question that received the highest satisfaction rating was "how well the pharmacists instruct you about how to take your medication" while the question that received the lowest satisfaction rating is "how well the pharmacist explain possible side effects of your medications to you". In comparing the satisfaction of individual pharmacies, pharmacy B received the highest satisfaction rating with a mean of 4.07. See details in Table-2 and Figure-1 below. 
Table-2: Scores for Patient Assessment with Pharmaceutical Services

\begin{tabular}{|l|l|}
\hline Item Questions (n=354) & Mean \pm SD \\
\hline How satisfied are you with the following; & \\
\hline Appearance of the pharmacy & $3.66 \pm 0.86$ \\
\hline The availability of the pharmacists to answer your questions & $3.73 \pm 0.84$ \\
\hline The pharmacists professional interaction with you & $3.69 \pm 0.87$ \\
\hline The attitude of the pharmacy staff & $3.71 \pm 0.84$ \\
\hline How well the pharmacists explain what your medication do & $3.78 \pm 0.93$ \\
\hline How well the pharmacists instruct you about how to take your medications & $4.11 \pm 0.88$ \\
\hline The overall services of the pharmacists & $3.74 \pm 0.78$ \\
\hline How well the pharmacist answers your questions & $3.77 \pm 0.82$ \\
\hline The pharmacist's effort to solve problems that you might have with your medications & $3.67 \pm 0.88$ \\
\hline The privacy of your conversations with the pharmacists & $3.60 \pm 0.98$ \\
\hline How well the pharmacist explains possible side effects of your medications to you & $3.46 \pm 1.04$ \\
\hline Mean Response & $\mathbf{3 . 7 2 \pm 0 . 8 8}$ \\
\hline
\end{tabular}

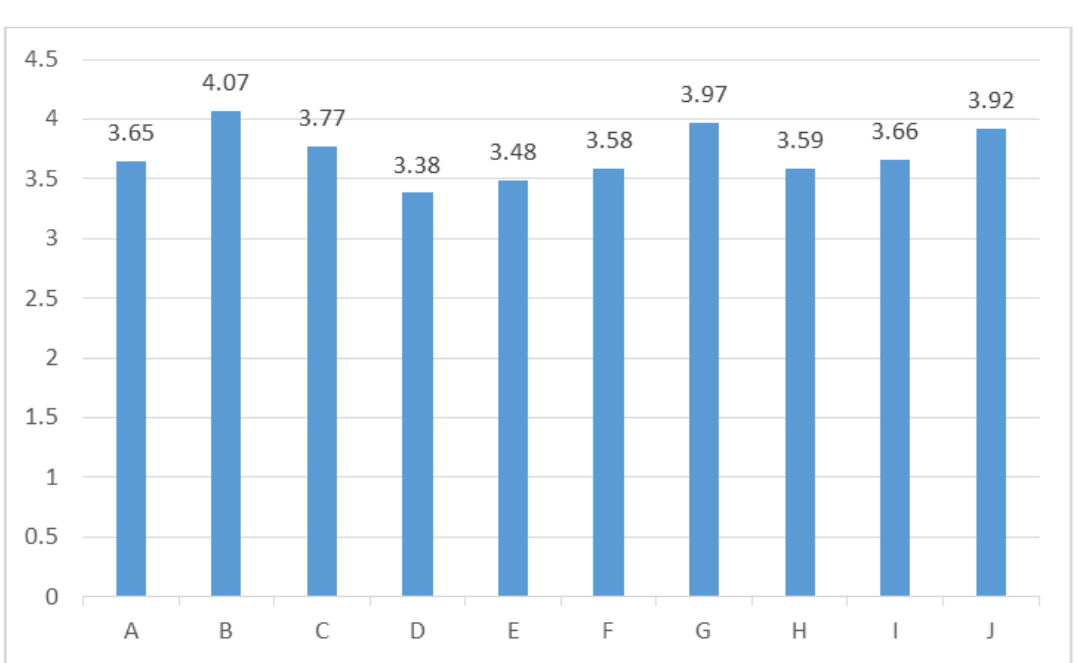

Fig-1: Mean response for the individual 10 pharmacies ( $\mathrm{A}-\mathrm{J}$ represent pharmacy 1 to 10)

\section{Student T test for Patient Satisfaction}

Inferential statistics was conducted to compare the satisfaction obtained from Pharmacy B that has the higher satisfaction with the other pharmacies and it was observed that the difference in the mean for six of the pharmacies were statistically significant as $P$ value was $<0.05$. See details in Table- 3 below.

Table-3: Student T test for Patient Satisfaction

\begin{tabular}{|l|l|l|l|l|l|}
\hline Pharmacy & 95\% Confidence Interval of the Difference & T & DF & $P$-Value \\
\hline & Lower & Upper & & & \\
\hline B-A & 0.11626 & 0.72465 & 2.796 & 39 & 0.008 \\
\hline B-C & -0.02262 & 0.63626 & 1.884 & 39 & 0.067 \\
\hline B-D & 0.35507 & 1.27302 & 3.688 & 21 & 0.001 \\
\hline B-E & 0.20717 & 1.06556 & 3.354 & 9 & 0.008 \\
\hline B-F & 0.21400 & 0.77019 & 3.564 & 45 & 0.001 \\
\hline B-G & -0.06230 & 0.40680 & 1.543 & 18 & 0.140 \\
\hline B-H & 0.26435 & 0.70403 & 4.436 & 45 & 0.0001 \\
\hline B-I & 0.24048 & 0.64795 & 4.397 & 43 & 0.0001 \\
\hline B-J & -0.09687 & 0.40923 & 1.249 & 38 & 0.219 \\
\hline
\end{tabular}

$P$-value $\leq 0.05$ is significant.

\section{Reliability of Patient's Satisfaction}

The factor loading for the instrument ranges from 0.539 to 0.753 while the Cronbach's alpha for the instrument is 0.899 as shown in Table-4. 


Table-4: Reliability of patient's satisfaction instrument
\begin{tabular}{|l|l|l|}
\hline Item Questions (n=354) & $\begin{array}{l}\text { Loading } \\
\text { factor }\end{array}$ & $\begin{array}{l}\text { Cronbach's } \\
\text { Alpha }\end{array}$ \\
\hline How satisfied are you with the following; & & 0.899 \\
\hline Appearance of the pharmacy & 0.753 & \\
\hline The availability of the pharmacists to answer your questions & 0.604 & \\
\hline The pharmacist's professional interaction with you & 0.705 & \\
\hline The attitude of the pharmacy staff & 0.729 & \\
\hline How well the pharmacists explain what your medication do & 0.642 & \\
\hline How well the pharmacists instruct you about how to take your medications & 0.617 & \\
\hline The overall services of the pharmacists & 0.784 & \\
\hline How well the pharmacist answers your questions & 0.572 & \\
\hline The pharmacist's effort to solve problems that you might have with your medications & 0.579 & \\
\hline The privacy of your conversations with the pharmacists & 0.539 & \\
\hline How well the pharmacist explains possible side effects of your medications to you & 0.717 & \\
\hline
\end{tabular}

\section{DISCUSSION Demography}

More males participated in the study as the males were slightly higher than the females, the higher numbers of males in this study could be a reflection of Nigeria's population which has a ratio of 102.58 males per 100 females [18]. However, previous Nigerian study conducted to assess patient satisfaction with community pharmacies has reported a higher female participating in the study [13]. The higher number of females is in contrast to previous findings that females do visit health facilities more often than males [19]. Majority of the respondents had post-secondary education which shows they are literate and at such high expectation of pharmaceutical care should be expected from them [20]. Respondent between the age group of 26 to 30 years participated more in the study.

\section{Satisfaction Assessment}

The validity of the instrument was determined to be 0.899 , the validity is in line with that of Larson $e t$ al., and also correspond to the result obtained from a validated Nigerian study [10]. Patient satisfaction was assessed on the basis of patients' perception and attitude of service provider [21-23]. The level of satisfaction was above average for all the items assessed, indicating that patients were satisfied with the services been rendered to them by pharmacists within Abuja metropolis and this is in agreement with other research findings carried out in Nigeria which reported high level of satisfaction of patients with pharmaceutical care services in community pharmacy [14]. The level of satisfaction received by these patients indicated that pharmacists within Abuja metropolis are living up to their responsibilities as prescribed by the World Health Organisation (WHO) and International Federation of Pharmacist (FIP). Other similar studies that aimed at assessing patient satisfaction with pharmaceutical care in community pharmacies in many parts of the world have reported high level of satisfaction by the patients [24, 21, 25]. Ware et al., [26] reported that satisfaction rating should be used to measure quality of care from the perspective of the patient and of which pharmacists are regarded as the most accessible health care provider. Patient satisfaction is a frequently reported humanistic outcome and it serves as an important determinant of the viability and sustainability of health care services [27]. Patient satisfaction can lead to more effective utilisation of health care resources. Evidence has shown that satisfied patients are more likely to continue using health care services, value and maintain relationships with health care providers, adhere to treatment and have a better outcome [28, 6, 29, 23]. Patient evaluations can help to identify needs, perceptions concern and areas of service failure and will serve as an avenue which will encourage health care providers to be accountable for quality of service delivered [30]. Patient satisfaction is therefore an important indicator of the quality of service delivered and it can act as a vital tool for continuous monitoring and quality improvement in health care delivery system. Satisfaction was anchored on a scale of 1 to 5 and 3 was taken as the midpoint, the mean response for all the responses was $3.72 \pm 0.88$ which was above the midpoint. The item that received the highest satisfaction rating was "how well the pharmacists instruct you about how to take your medications" with a mean score of 4.11. This reported high level of satisfaction to this question may be due to the fact that pharmacists are the only drug experts and at such they always give patients the direction for use of any medication dispensed.

The level of satisfaction received by the patients varies from pharmacy to pharmacy as revealed by this study, of which other similar studies have also reported differences in rating, with some community pharmacies receiving higher ratings than others [24]. In this study, Patients who visited pharmacy B gave the highest rating while pharmacy $\mathrm{D}$ received the lowest rating as seen in Figure-1. The difference in the satisfaction obtained was statistically significant as seen in Table-3 which indicates that satisfaction varies across different pharmacies. 


\section{CONCLUSION}

The study revealed that patients were satisfied with the level of care being given to them by the community pharmacists within the city of Abuja. It is worthy to note that pharmacists are living up to their responsibilities in the aspect of patient satisfaction despite the high level of expectation from the patients. However, more effort should be put in place to increase the level of care given to patients due to the fact that patients' expectation will always increase. More training is therefore recommended for pharmacists in order to meet patients' need at every point in time.

\section{REFERENCES}

1. Kleinmann K. We really do care. American Journal of Health-System Pharmacy. 1994 Aug 15;51(16):2011-5.

2. Oparah AC. Models of Pharmacy Practice. Essential of Pharmaceutical Care. 2010; 115-125.

3. Hepler CD, Strand LM. Opportunities and responsibilities in pharmaceutical care. American journal of hospital pharmacy. 1990 Mar 1;47(3):533-43.

4. APhA. American Pharmaceutical Association principles for the Practice of Pharmaceutical Care. Rovers JP (Ed.). American Pharmaceutical Association, Washington DC. 1996; 76-83.

5. Cipolle RJ, Strand LM, Morley PC. Pharmaceutical Care practice. McGraw-Hill NY; 1998;76-83.

6. Pascoe GC. Patient satisfaction in primary health care: a literature review and analysis. Eval Program Plann. 1983;6(3-4):185-210.

7. Rubin HR, Gandek B, Rogers WH. Patients' ratings of outpatient visits in different practice settings: results from Medical outcomes study. JAMA; 1998; 270: 835-840.

8. Cleary PD, McNeil BJ. Patient Satisfaction as an indicator of quality care. Inquiry; 1998; 25:25-36.

9. Farris KB, Kirking D. Assessing the Quality of Pharmaceutical Care I: One perspective of quality. Ann Pharmacother; 1993; 27: 68-73.

10. Oparah AC, Enato EF, Akoria OA. Assessment of patient satisfaction with pharmaceutical services in a Nigerian teaching hospital. International Journal of Pharmacy Practice. 2004 Mar;12(1):7-12.

11. Onavbavba G, Owonaro AP, Eniojukan FJ. Patient Satisfaction with Pharmaceutical Care Services in Selected Health Facilities in Delta State, SouthSouth of Nigeria. Ortho \& Rheum Open Access: 2017; 8(3):555-739.

12. Eze IHC, Ojieabu WA, Eze MSC. Older adults' satisfaction with pharmaceutical care in an outpatient pharmacy of a Nigerian teaching hospital. Journal of Science and Practice of Pharmacy. 2018; 5(2): 240-248.

13. Owonaro AP, Eniojukan FJ, Owonaro AD, Ebinyo CN. Assessment of patient satisfaction with pharmaceutical services in a hospital in Bayelsa state south-South of Nigeria. Ortho \& Rheum Open Access. 2017;6(3):555-686.

14. Owonaro AP, Eniojukan FJ, Owonaro AED, Ebinyo CN. Assessment of Patient Satisfaction with Pharmaceutical Services in Community Pharmacies in Bayelsa State South- South of Nigeria. Glob Journal Pharmaceu Science, 2017; 2(3):555-589.

15. Oparah AC, Adje DU, Enato EF. Outcomes of pharmaceutical care intervention to hypertensive patients in a Nigerian community pharmacy. International Journal of pharmacy practice. 2006 Jun;14(2):115-22.

16. Oparah AC, Kikanme LC. Consumer satisfaction with community pharmacies in Warri, Nigeria. Research in Social and Administrative Pharmacy. 2006 Dec 1;2(4):499-511.

17. Larson LN, Rovers JP, MacKeigan LD. Patient satisfaction with pharmaceutical care: update of a validated instrument. Journal of the American Pharmaceutical Association (1996). 2002 Jan 1;42(1):44-50.

18. Nigeria Bureau of Statistics. Statistical Report on Women and Men in Nigeria, 2015. Available on website:

http://www.nigerianstat.gov.ng/download/491 (Accessed 19th January 2020)

19. Kothari CL, Rohs T, Davidson S, Kothari RU, Klein C, Koestner A, DeBoer M, Cox R, Kutzko K. Emergency department visits and injury hospitalizations for female and male victims and perpetrators of intimate partner violence. Advances in emergency medicine. 2015;2015.

20. Ayalew MB, Taye K, Asfaw D, Lemma B, Dadi F, Solomon H, Tazeze H, Tsega B. Patients'/clients' expectation toward and satisfaction from pharmacy services. Journal of research in pharmacy practice. 2017 Jan;6(1):21-26.

21. Panvelkar PN, Saini B, Armour C. Measurement of patient satisfaction with community pharmacy services: a review. Pharmacy world \& science. 2009 Oct 1;31(5):525-37.

22. Kradjen WA, Schulz R, Christensen DB, Stergachis A, Sullivan S, Fullerton DP, Sturm L, Schneider G. Patients' perceived benefit from and satisfaction with asthma-related pharmacy services. Journal of the American Pharmaceutical Association (1996). 1999 Sep 1;39(5):658-66.

23. Schommer JC, Kucukarslan SN. Measuring patient satisfaction with pharmaceutical services. American journal of health-system pharmacy: AJHP: official journal of the American Society of Health-System Pharmacists. 1997 Dec;54(23):2721-32.

24. Briesacher B, Corey R. Patient satisfaction with pharmaceutical services at independent and chain pharmacies. American Journal of Health-System Pharmacy. 1997 Mar 1;54(5):531-536.

25. Al-Arifi MN. Patients' perception, views and satisfaction with pharmacists' role as health care 
provider in community pharmacy setting at Riyadh, Saudi Arabia. Saudi Pharmaceutical Journal. 2012 Oct 1;20(4):323-30.

26. Ware JE, Davies AR, Rubin HR. Patients' assessments of their care. In: The quality of medical care: information for consumers. Washington, DC: U.S. Office of Technology Assessment, 1988:231-47; publication no. OTAH-386.

27. Johnson J. A comparison of satisfaction with mail versus traditional pharmacy services. Journal of Managed Care Pharmacy. 1997 May;3(3):327-37.
28. Locker D, Dunt D. Theoretical and methodological issues in sociological studies of consumer satisfaction with medical care. Soc Sci Med. 1978;12(4A):283-92

29. Aharony L, Strasser S. Patient satisfaction: what we know about and what we still need to explore. Med Care Rev. 1993;50(1):49-79.

30. Ford RC, Bach SA, Fottler MD. Methods of measuring patient satisfaction in health care organizations. Health Care Manag (Frederick). 1997;22(2):74-89. 